\title{
Study on the Innovative Methods of Construction Project Safety Management

\author{
${\text { Lin } \mathrm{Jie}^{1} \text { and Liao Jinsong }}^{2}$ \\ ${ }^{1,2}$ Chongqing Jianzhu College, 400072 China
}

Keywords: Construction project; Safety management; Innovation; Methods

\begin{abstract}
Currently, some developed countries have already formulated and implemented a sophisticated category of construction laws and regulations based on their own development characteristic, effectively reducing the accident occurrence. In contrast, although China has promulgated and implemented some relevant laws and regulations on construction projects, but there are still many safety problems concerning construction management in this regard. In this paper, the author analyzed the existing problems of our construction projects, and put forward a more comprehensive management system drawing on the experience of successful construction project management abroad.
\end{abstract}

\section{Introduction}

As a more complex division of management family, construction project management is related to many different departments such as design department, the owner units, construction department, supervision department, etc. In recent years, because of the continuous development of construction industry and the increasing trend of accident frequency, the government has strengthened its supervision but gains little effect. This paper believes that new methods shall be adopted in construction management in view of the characteristic of safety management, including set up a voluntary contract and a "community engagement" model on construction enterprise safety management.

\section{The Concept and Role of Construction Safety Management}

The safety management of construction engineering includes all the activities securing the construction process, its main purpose is to control all the risk trigger and reduce or even eliminate the possibility of risk, fundamentally guaranteeing the achievement of the expected benefits. The construction process have the characteristics of poor working environment, high accident occurrence, technically demanding process and high labor intensity; each contains certain risk factors. Therefore, enterprises should strengthen safety management to ensure the value realization of the entire construction project and ensure the further development of the construction business, its economic benefits as well as credibility as safety management to some extent reflects the overall management level of the enterprise.

\section{Analysis of Current Situation in Construction Safety Management}

Safety Management Concept of Constructing Enterprise. Usually, construction enterprises possess a wrong concept of safety management and don't exert enough emphasis on safety management, many believe that construction progress control is more important than safety management, many companies even believe that the cost devoted in safety management is useless or a waste. Therefore, in order to maximize economic benefits, they continued to reduce investment in safety management, personnel safety education and training, security supplies etc. In return, the lack of safety management concept leading to the lack of these essential inputs, which further results in inefficient safety management. Construction quality and construction accident are two hidden danger threatening the social reputation and credibility of a construction enterprise. However, many enterprises don't fully implement the construction concept of safety first and people foremost 
into their safety management job, which shows a lack of insight and long term prospect.

Laggard Construction Safety Management Methods. Due to the ignorant of safety management, many construction enterprises do not have systematic safety management methods; some with one just take it as decoration to deal with the examination of local administrative department and do not implement it into practice, especially as there's no unified industry standard and grade evaluation system. As a result, many construction personnel have no knowledge of safety construction and their work is lack of standardization. Take the key cultural project of a province as example, the project area reached $284530 \mathrm{~m}^{2}$ and major construction companies take the responsibility of a construction task of nearly 20,000 square meters. However, according to the media exposure, the safety director not only has no educational background, but also lack of security management experience.

Safety Management Personnel and Construction Workers Lacking of Safety Awareness. Currently, many construction companies ignore safety knowledge training on safety management personnel and construction personnel. Therefore many management personnel are lack of safety awareness themselves, conducting the construction process without following the mandatory standards prescribed by the State. In consequence, various illegal operations become a quite normal phenomenon. As a lot of outdoor construction, high place construction, and fly-over crossing construction are involved in the construction process, unexpected incidents are more likely to emerge. Beside, many management personnel have blind optimism and fluke mind, which results in many defects in safety management. Lacking of security protection and ignorant of safety training make it difficult to curb the occurrence of construction accidents. For example, on December 29, 2014, the under-constructed Stadium of Tsinghua University affiliated High School suddenly collapsed, which exhibits an example of those don't construct in accordance with the construction requirements, resulting in 10 deaths and four injuries.

Inadequate Supervision on Safety Management. Many construction enterprises appointed those with little educational background as the safety supervision administrator and didn't stipulate a concrete process and a clear mandate for supervision, therefore the safety supervision becomes a common vulnerability. When spotting safety loopholes, some supervision administrators only give a verbal warning without recording these foul play and giving punishment to those dangerous irregularities. Although many construction companies cooperate with some special supervision units, but there still exists the phenomenon of oversight and untimely investigation of security risks. In some cases, the supervision units and construction units have same interest, leading to the oversight or negligence of the administrator and ineffective supervision.

\section{Innovative Methods of Construction Project Safety Management}

Innovations on Safety Management Model of Construction Project. Set Up a Voluntary Contract On Construction Enterprise Safety Management. Although there are lot regulations on construction safety management in Chinese Law on Safety in Production, only those mandatory provisions have been enforced by the construction enterprises that have little safety management knowledge and few input in safety protection. Therefore, there is a great gap between the safety technical specification of construction projects and its implementation situation. To narrow this gap, the voluntary contract on construction enterprise safety management provides an innovative security management method, which stipulates the security responsibilities and obligations of construction enterprise. This voluntary agreement can address current construction safety regulation problems and specify the content of enterprise security management, realizing a balance between public administration and economic administration, between construction project and national administration. Besides, it can also increases the enthusiasm of construction enterprise safety management, safety assessment and realizes the final goal of safety management - no casualty.

Set Up a "Community Engagement" Model of Construction Enterprise Safety Management. Currently the communication gap between security officers and construction workers isolation lead to some conflicts in project safety management in terms of project resources, schedule, cost and the incoordination between security maintenance and construction schedule. The "community 
engagement" model presents a multi-level, new security management model which takes the basic unit of the city, the community, as the center and constructs a mutual participation model of construction enterprise, community people and supervisory organization. "Community engagement" model takes advantage of the convenience of community management and the objectivity of community supervision, timely discovering and solving safety problems. However, this model isn't self-existent, it needs some other elements to complement and improve, for example, the knowledge background of the construction personnel and corporate culture. Under this community engagement model, the construction enterprise should give safety knowledge training and security ideological education at regular intervals. Besides, the construction should cultivate positive and optimistic corporate culture. Under the mutual influence of outsider systematic theory and the inner safety consciousness, the community engagement model can achieve the maximum utility.

\section{Innovations on Safety Management Institution of Construction Project.}

Rights and Liabilities Distribution System. Various construction business units are involved in the constructing process, such as design units, testing units, survey units and supervision units, etc. In order to achieve maximum profit and minimum cost, each unit may not fully implement their duty, such as the design units give a rather rough design sketch, the supervision units only go through the motions, the survey units give a wrong data and the construction unit catch up with progress blindly without thinking of our current situation. Therefore, a rights and liabilities distribution system should be established to clarify the duty of each unit. For example, the construction units should be responsible for the implementation of technical standards for safety in compliance with safety rules and regulations; the owner units should take responsibility for design, survey and supervision; the supervision units should be given the obligation of testimony.

Security Liability Insurance System. Currently, the insurance industry has already set foot in the field of construction safety management. Under this circumstance, we should continue to deepen the reform and innovation in safety liability insurance system, in order to avoid construction personnel security accident and casualties of personnel. Meanwhile, in order to enhance the safety consciousness of the overall personnel and management leaders in the construction enterprise and improve the working efficiency and working quality, different rank of insurance premium should be designed for different construction unit, such as those with good safety performance and high credibility shall have less insurance costs, while those with poor performance and low credibility shall pay a much higher insurance fee. The implementation of security liability insurance system has a significant meaning for construction industry and construction personnel. Firstly, it serves as a strong supplement for employment injury insurance and offset the defects of social insurance. Secondly, its implementation can spur the enterprise paying more attention on safety management and enhancing safety protection. Lastly, security liability insurance system has a better social insurance function and protects both the rights of the construction enterprise and the working personnel.

Security Performance Evaluation System. Presently, Chinese construction enterprise still has a long way to go in terms of safety performance evaluation. Although most enterprise can conduct assessment and evaluation following the guidance of Construction Enterprise Safety Production Evaluation Criterion, many safety quality problems still exist. In order to solve these problems, our country can learn from the advanced experience of foreign security quality assessment, combined with domestic construction safety practices, and explore a set of scientific, objective, advanced security performance evaluation system, as a complement of "Construction enterprise security evaluation criteria". The establishment and improvement of the evaluation system will not only help protect the business, construction workers and the interests of owners, but also help improve the theoretical and technical level of China's construction industry.

Innovations on Personnel Management of Construction Project. Overall, the safety management personnel have a relatively low level of expertise and little consciousness of responsibility, leading to the frequent occurrence of safety accidents. As the project security managers directly control the quality of safety management, whose every move should be accord 
with relevant provisions, therefore some job should be done to improve and strengthen their working capacity and working model. First, the management staff should be trained to improve their professional knowledge and quality of service; second, their practical working ability and skills should be further strengthened; third, an inspection and monitoring mechanism should be established to improve the level of service and quality of their work.

\section{Summary}

In summary, this paper gives a detailed analysis on the existing problems of safe management in China's construction projects based on various construction project management theories and through multiple research approaches, and innovatively proposes some methods of construction project safety management, which is more effective and easy to realize compared with conventional approaches.

\section{References}

[1] Zhao Ming. A Tentative Study on the Innovation Measures of Construction Project Safety Management System [J]. Chinese OverseasArchitecture.2013 (01)

[2] Chen Lina. Study on Security Risk Field Theory of Construction Project and Its Application [J]. Intelligence .2012 (08)

[3] Liu Yang, Xin Ping. Appraisal of Safety Culture Establishment in Engineering Project [J]. Construction and Design For Project .2012 (04)

[4] Wu Jianguo. Innovative Measures of Construction Project Safety Management [J]. Doors and Windows .2012 (07)

[5] Liu Jian. Research on Construction Project Safety Management [J]. Scientific Horizon. 2012(28)

[6]Cheng Lanhong. Methods of Construction Project Safety Control [J]. Chinese Urban Economics. 2012(01) 